\title{
Bizarre Parosteal Osteochondromatous Proliferation of the Skull in a Young Male
}

\author{
Radu Baz, Cosmin Niscoveanu* \\ Pozitron Medical Investigations, Constanta, Romania \\ Email: ${ }^{*}$ cosmin_niscoveanu@yahoo.com
}

Received August 1, 2012; revised January 2, 2013; accepted January 9, 2013

Copyright (C) 2013 Radu Baz, Cosmin Niscoveanu. This is an open access article distributed under the Creative Commons Attribution License, which permits unrestricted use, distribution, and reproduction in any medium, provided the original work is properly cited.

\begin{abstract}
Bizarre parosteal osteochondromatous proliferation (BPOP), as defined by Nora and colleagues in 1983 (also called Nora lesion), is a rare lesion. About 160 cases of BPOP have been presented in the literature to date. The lesion is an exophytic outgrowth from the cortical surface consisting of bone, cartilage and fibrous tissue. These types of lesions have been reported mostly in the hands and feet. Localization at the level of the skull is extremely rare. We report a case of a young man with multiple Nora’s lesions with atypical localization in the skull and mandible.
\end{abstract}

Keywords: BPOP; Nora; CT; Skull

\section{Introduction}

Nora's lesion, also called bizarre parosteal osteochondromatous proliferation (BPOP), is a rare benign osseous tumor that presents exophytic cortical growth consisting of bone, cartilage, and fibrous tissue. It was first described by Nora and colleagues in 1983 [1]. It usually affects the proximal and middle phalanges, and the metacarpal or metatarsal bones. The hands are 4 times more commonly affected than the feet; however, lesions in other bones have been reported [2-4]. It usually affects patients in their 20s or 30s, with no sex predilection. This benign lesion can be mistaken for malignant processes because of the high frequency of recurrence, the potential rapid growth and atypical histologic appearance. We report a case of a young man with multiple Nora's lesions with atypical localization in the skull and mandible. From our knowledge this is the second case in the literature with BPOP in the mandible [5], and also we did not encounter other cases with such a spreading in the skull and jaw.

\section{Case Report}

A 22-years old male was referred to our imaging center for a computed tomography of the skull for parotid space masses which appeared a few months ago, being more painful in the last weeks. He also reported a recent increase in the size of the masses. At clinical examination,

\footnotetext{
${ }^{*}$ Corresponding author.
}

the patient presented with mildly painful swelling at the level of parotid and submandibular space, bilaterally. Palpation revealed hard masses, $3-5 \mathrm{~cm}$ in diameter, immobile, with irregular surface, more proeminent on the left. The overlying skin was freely mobile. There was no obvious soft tissue redness or increased temperature. No other bone or joint pain was noticed, nor stiffness of the temporo-mandibular joint. He claimed to have no history of injury.

CT examination was performed on a Lightspeed VCT 64-slice system provided by GE Medical Systems. Noncontrast scans $(0.6 \mathrm{~mm})$ of the entire skull were acquired in a 2000:350 window. CT showed multiple infra- and supracentimetric osteochondroma-like lesions with lobulated well-defined borders and parosteal development at the level of left temporal bone, left ethmoid, calvaria, zygomatic arches, maxilla and mandible. Those masses associated cortical bone thickening, without interruption, and well delineation with compressive effect on soft tissues (Figures 1-3).

The patient underwent surgical treatment of the biggest and most painful lesion (left mandibular) with removal of the pseudocapsule and underlying periosteum excision. Morphopathological result was that of a lobulated, well-defined mass, with disorganized cartilage and patchy ossification, large chondrocytes and osteoblasts, without atypias.

Clinical and imaging findings were consistent with diagnosis of bizarre parosteal osteochondromatous proliferation, certified by morphopathological result. 

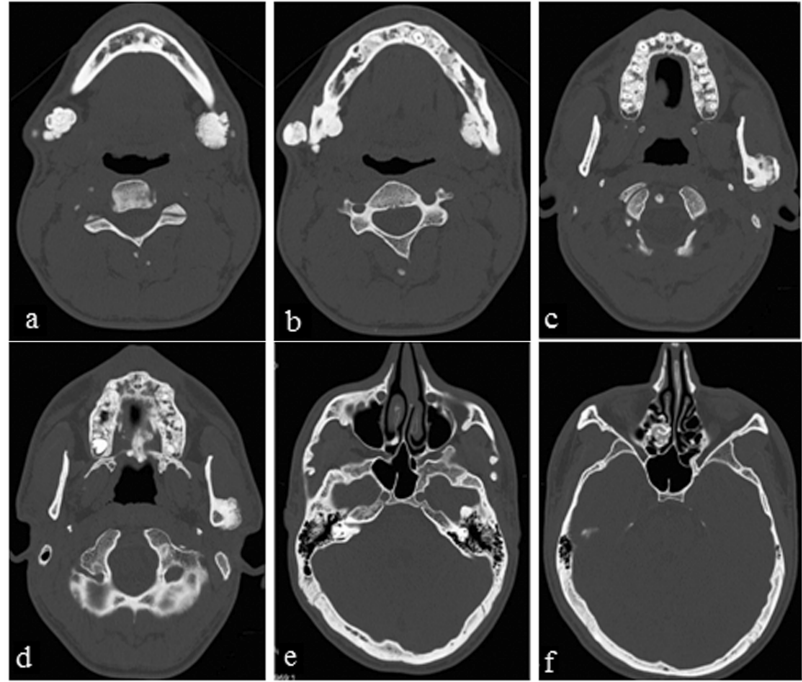

Figure 1. Axial CT-scans showing multiple lobulated welldefined lesions at the level of mandibular angles (a,b); left mandibular ramus (c,d); zigomatic arches (e) and ethmoidal bone (f).
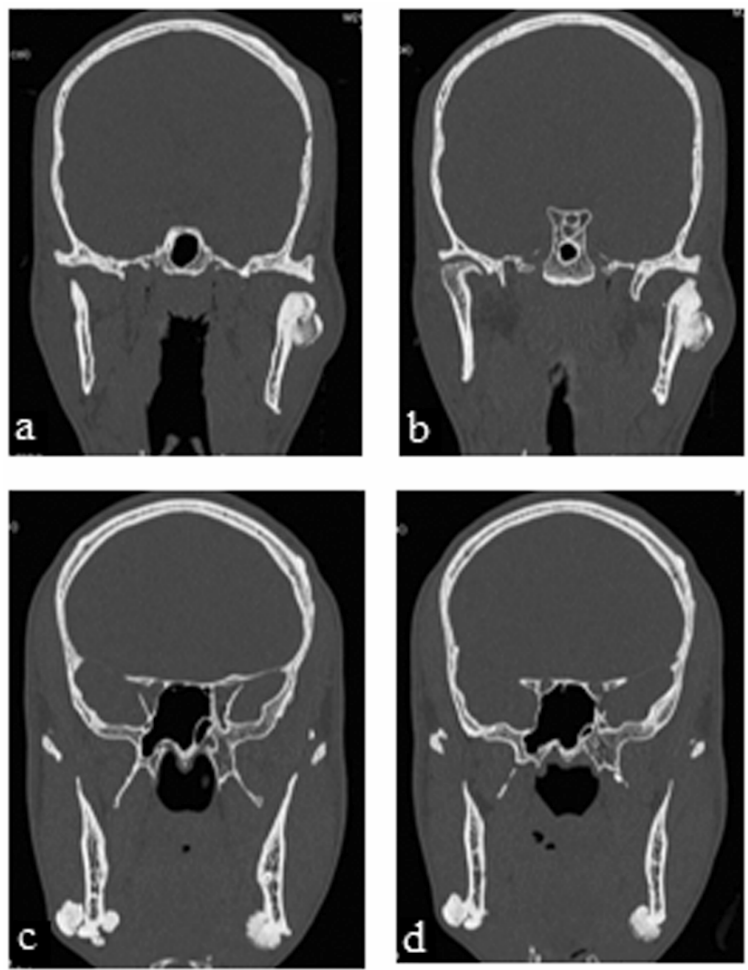

Figure 2. Coronal CT reformats showing the same mandibular lesions (a, b, c, d) and smaller ones at the level of calvaria (c,d), with heterogeneous structure and without continuation with normal cortical bone.

\section{Discussion}

Bizarre parosteal osteochondromatous proliferation (Nora's disease) is a rare benign lesion usually seen in young adults, although it can appear in any age group. It
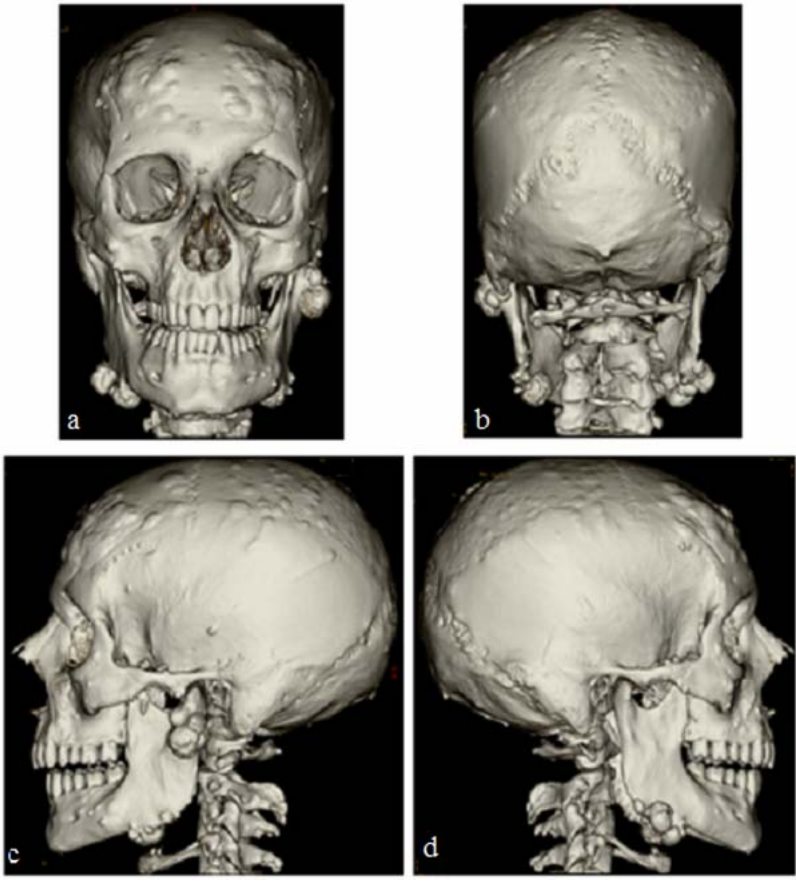

Figure 3. Volume rendering images indicating multiple hard masses in calvaria, maxillar bones and mandible (a,b,c,d).

affects men and women in equal proportions. Some authors believe the etiology is due to minor trauma but there is still no imaging or pathologic evidence to support this. Patients usually present with the history of a slowly growing mass or pain, as in our patient.

The following specific radiological findings help to distinguish BPOP from many of its mimickers including solitary osteochondroma:

1. The tumor appears to arise from the surface of the cortex directly.

2. There is no continuity between the central part of the tumor and the medulla of the underlying bone.

3 . There is no flaring of the cortex of the underlying bone [6].

On computed tomography scan, BPOP is typically well delineated without continuity with the cortex of the medullar canal, like in osteochondromas. The lesion may exhibit a spiculated or irregular surface leading to a possible misdiagnosis of malignancy such as osteosarcoma. In contrast to malignant lesions, BPOP exhibits no periosteal reaction and has normal radiological underlying bone and adjacent soft tissue.

BPOP has been described as a lesion with a nodular surface covered by glistening cartilage and a distinct blue tint of the bone within on gross examination. The periphery of the lesion contains lobulated hypercellular cartilage and fibrous tissue with occasional large chondrocytes. There are uniform osteoblasts on the bony trabeculae. Chondrocytes may be binucleated and prolifera- 
tion of bizarre (even spindle shaped) fibroblast in the intertrabecular spaces of disorganized bone has been reported. Typically the cartilage lobules show mild atypia and moderate mitotic activity is seen in the spindle cells. This often confuses the diagnosis and the lesion needs to be distinguished from conventional osteosarcoma, lowgrade parosteal osteosarcoma, and chondrosarcoma. There is no "columnation" of the cartilage as in osteochondroma, rather the cartilage is disorganized and irregular, with patchy areas of ossification [7].

The recommended treatment of choice is excising the pseudocapsule over the lesion, any periosteal tissue beneath the lesion, and decorticating any abnormal appearing areas in the underlying host bone, as this procedure has less recurrence rate than simple excision of the lesion [8].

These lesions have a remarkable tendency to recur: recurrence rates between $29 \%$ and $55 \%$ in a 2-year interval have been reported, and almost half of those patients have had a second recurrence. [9] Nora and colleagues presented 35 cases of BPOP with 18 (51\%) local recurrences [1]. Meneses and colleagues reported a recurrence rate of $55 \%$ in a series of 65 patients [2] and Dhondt and colleagues reported a recurrence rate of $29 \%$ in 24 patients [10]. However, despite a high tendency to recur and a sometimes atypical histological appearance, no malignant transformation, metastases, deaths or associated systemic diseases have been described so far in patients with BPOP.

\section{Conclusion}

Nora's lesion represents a distinct radio-pathological entity. It should be considered whenever the diagnosis of osteochondroma is made. Being a rare lesion, the diagnosis of Nora's lesion is challenging for most radiologists and pathologists as illustrated by this case and others. The particularity of our case is the distinct localization of the lesions, with very few cases of BPOP of the skull being reported.

\section{REFERENCES}

[1] F. E. Nora, D. C. Dahlin and J. W. Beabout, "Bizarre
Parosteal Osteochondromatous Proliferation of the Hands and Feet," The American Journal of Surgical Pathology, Vol. 7, No. 3, 1983, pp. 245-250. doi:10.1097/00000478-198304000-00003

[2] M. F. Meneses, K. K. Unni and R. G. Swee, "Bizarre parosteal Osteochondromatous Proliferation of Bone (Nora's Lesion)," The American Journal of Surgical Pathology, Vol. 17, No. 7, 1993, pp. 691-697. doi:10.1097/00000478-199307000-00006

[3] L. Abramovici and G. C. Steiner, "Bizarre Parosteal Osteochondromatous Proliferation (Nora's Lesion): A Retrospective Study of 12 Cases, 2 Arising in Long Bones," Human Pathology, Vol. 33, No. 12, 2002, pp. 1205-1210. doi:10.1053/hupa.2002.130103

[4] M. Boussouga, A. Harket, N. Bousselmame and K. Lazrak, "Bizarre Parosteal Osteochondromatous Proliferation (Nora's Lesion) of the Forefoot,” Acta Orthopaedica Belgica, Vol. 74, No. 4, 2008, pp. 562-565.

[5] H. M. Dashti, J. D. Reith, B. J. Schlott, E. L. Lewis, D. M. Cohen and I. Bhattacharyya, "Bizarre Parosteal Osteochondromatous Proliferation (Nora's Lesion) of the Mandible. A Rare Bony Lesion,” Head and Neck Pathology, Vol. 6, No. 2, 2012, pp. 264-269. doi:10.1007/s12105-011-0311-X

[6] J. Q. Ly, L. T. Bui-Mansfield and D. C. Taylor, "Radiologic Demonstration of Temporal Development of Bizarre Parosteal Osteochondromatous Proliferation,” Clinical Imaging, Vol. 28, No. 3, 2004, pp. 216-218. doi:10.1016/S0899-7071(03)00235-3

[7] B. Moretti, A. DiGiovanni, F. Martino, L. Moretti, et al., "Nora's Lesion. Clinical and Therapeutic Consideration," La Chirurgia degli Organi di Movimento, Vol. 92, No. 1, 2008, pp. 45-49. doi:10.1007/s12306-008-0038-3

[8] F. Garcia-Alvarez, A. F. Lacleriga, A. L. Bueno, T. Castiella and F. Seral, "Bizarre Parosteal Osteochondromatous Proliferation. Difficulty in Diagnosis," La Chirurgia degli Organi di Movimento, Vol. 84, No. 2, 1999, pp. 179-182.

[9] S. Bandiera, P. Bacchini and F. Bertoni, "Bizarre Parosteal Osteochondromatous Proliferation of Bone,” Skeletal Radiology, Vol. 27, No. 3, 1998, pp. 154-156. doi:10.1007/s002560050355

[10] E. Dhondt, L. Oudenhoven, S. Khan, et al., "Nora’s Lesion, a Distinct Radiological Entity?” Skeletal Radiology, Vol. 35, No. 7, 2006, pp. 497-502. doi:10.1007/s00256-005-0041-9 